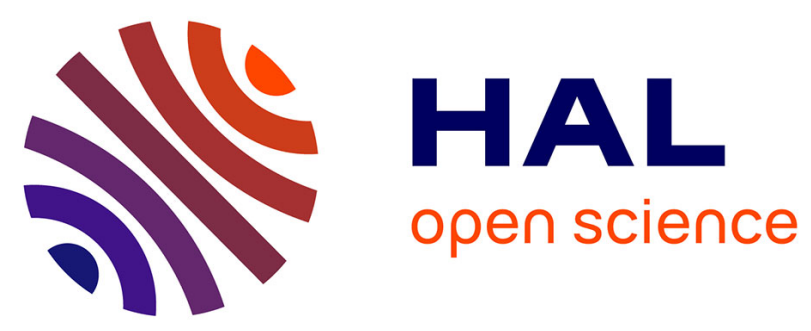

\title{
Letter to the Editor: Acute extrahepatic infectious or inflammatory diseases are a cause of transient mosaic pattern on CT and MR imaging related to sinusoidal dilatation of the liver
}

Lionel Arrivé, Ramiro Orta, Nikias Colignon, Sanaa El Mouhadi, Yves Menu

\section{To cite this version:}

Lionel Arrivé, Ramiro Orta, Nikias Colignon, Sanaa El Mouhadi, Yves Menu. Letter to the Editor: Acute extrahepatic infectious or inflammatory diseases are a cause of transient mosaic pattern on CT and MR imaging related to sinusoidal dilatation of the liver. European Radiology, 2016, 26 (12), pp.4325 - 4326. 10.1007/s00330-016-4295-5 . hal-01400038

\section{HAL Id: hal-01400038 \\ https://hal.sorbonne-universite.fr/hal-01400038}

Submitted on 21 Nov 2016

HAL is a multi-disciplinary open access archive for the deposit and dissemination of scientific research documents, whether they are published or not. The documents may come from teaching and research institutions in France or abroad, or from public or private research centers.
L'archive ouverte pluridisciplinaire HAL, est destinée au dépôt et à la diffusion de documents scientifiques de niveau recherche, publiés ou non, émanant des établissements d'enseignement et de recherche français ou étrangers, des laboratoires publics ou privés. 
Letter in reply

Letter to the Editor: Acute extrahepatic infectious or inflammatory diseases are a cause of transient mosaic pattern on CT and MR imaging related to sinusoidal dilatation of the liver

Lionel Arrivé, Ramiro Orta, Nikias Colignon, Sanaa El Mouhadi, Yves Menu

Department of Radiology, Saint-Antoine Hospital, Assistance Publique-Hôpitaux de Paris, 184 Rue du Faubourg Saint-Antoine, 75012 Paris, France and Sorbonne Universités, UPMC Université Paris 06, Faculté de Médecine Pierre et Marie Curie

Corresponding author:

Lionel Arrivé

lionel.arrive@sat.aphp.fr

Fax: 33 (1) 49282259

Phone: 33 (1) 49282258 
We read with great interest the article by Doctor Ronot and colleagues in the recent issue of European Radiology about the transient mosaic pattern observed on CT and MR imaging in acute extrahepatic infection or inflammatory disease (1). They nicely demonstrated that acute diseases of extrahepatic organs were associated with a reversible hepatic sinusoidal dilatation resulting in a mosaic enhancement pattern on contrast-enhanced CT or MR imaging. However, we were surprised that other hepatic imaging features such as periportal halo or gallbladder wall thickening were not mentioned. Basically, it is uneasy to estimate the frequency of such hepatic abnormalities in patients with acute extrahepatic infection condition.

Han GH et al reported 46 patients with hepatobiliary changes from a group of 157 patients with acute pyelonephritis (2). They found 46 patients (29\%) with early inhomogeneous hepatic enhancement, 15 patients $(10 \%)$ with periportal low density halo and 6 patients $(4 \%)$ with gallbladder wall thickening (2). Zissin et al. reported a gallbladder wall thickening in 19 of 33 patients $(58 \%)$ with acute pyelonephritis, a periportal hypodense halo in $17(51 \%)$ patients and a congested liver in 3 (9\%) patients (3). Vollmann R. et al reported 29 patients (11\%) with a periportal hypodense halo from a group of 274 patients with acute pyelonephritis (4).

In our own experience we analyzed the results of contrast-enhanced CT at portal phase in 19 patients with various extrahepatic infectious conditions exhibiting hepatic abnormalities. Hepatic abnormalities included periportal hypodense halo in 18, a transient mosaic pattern in 14 and a gallbladder wall thickening in 6 of the 19 patients (Fig. 1). Respective frequencies of hepatobiliary changes observed in patients with extrahepatic infectious conditions appear to be markedly variable. Such differences may be explained by many differences between published studies including severity and nature of primary extrahepatic infectious condition, characteristics of contrast-enhanced CT scan (i.e. arterial vs portal phase) and retrospective design of studies with marked variability of inclusion criteria. As Doctor Ronot and colleagues, we believe that such various hepatobiliary changes related to extrahepatic infections condition should be recognized to avoid misdiagnosis with primary hepatic disease such as acute hepatitis, cholangitis or cholecystitis.

1. Ronot M, Kerbaol A, Rautou PE et al. Acute extrahepatic infectious or inflammatory diseases are a cause of transient mosaic pattern on CT and MR imaging related to sinusoidal dilatation of the liver. Eur Radiol DOI 10.1007/s00330-015-4124-2

2. Han GH, Lee NK, Kim S et al. Septic liver: clinical relevance of early inhomogeneous enhancement of the liver in patients with acute pyelonephritis. Acta Radiologica 2013;54:975-980

3. Zissin R, Osadchy A, Gayer G et al. Extrarenal manifestations of severe acute pyelonephritis: CT findings in 21 cases. Emerg Radiol 2006;13:73-77

4. Vollmann R, Schaffler GJ, Spreizer C et al. Clinical significance of periportal tracking as an extrarenal manifestation of acute pyelonephritis. Abdom Imaging 2011;36:557-560 
Figures legends:

Figure 1: 21-year old man with severe enterobacter cloacae colitis. Mosaic enhancement pattern and periportal low density halo are well demonstrated in transverse plane (a). A marked thickening of gallbladder wall is demonstrated in frontal plane (b). Follow-up CT scan one month later (not shown) was normal. 

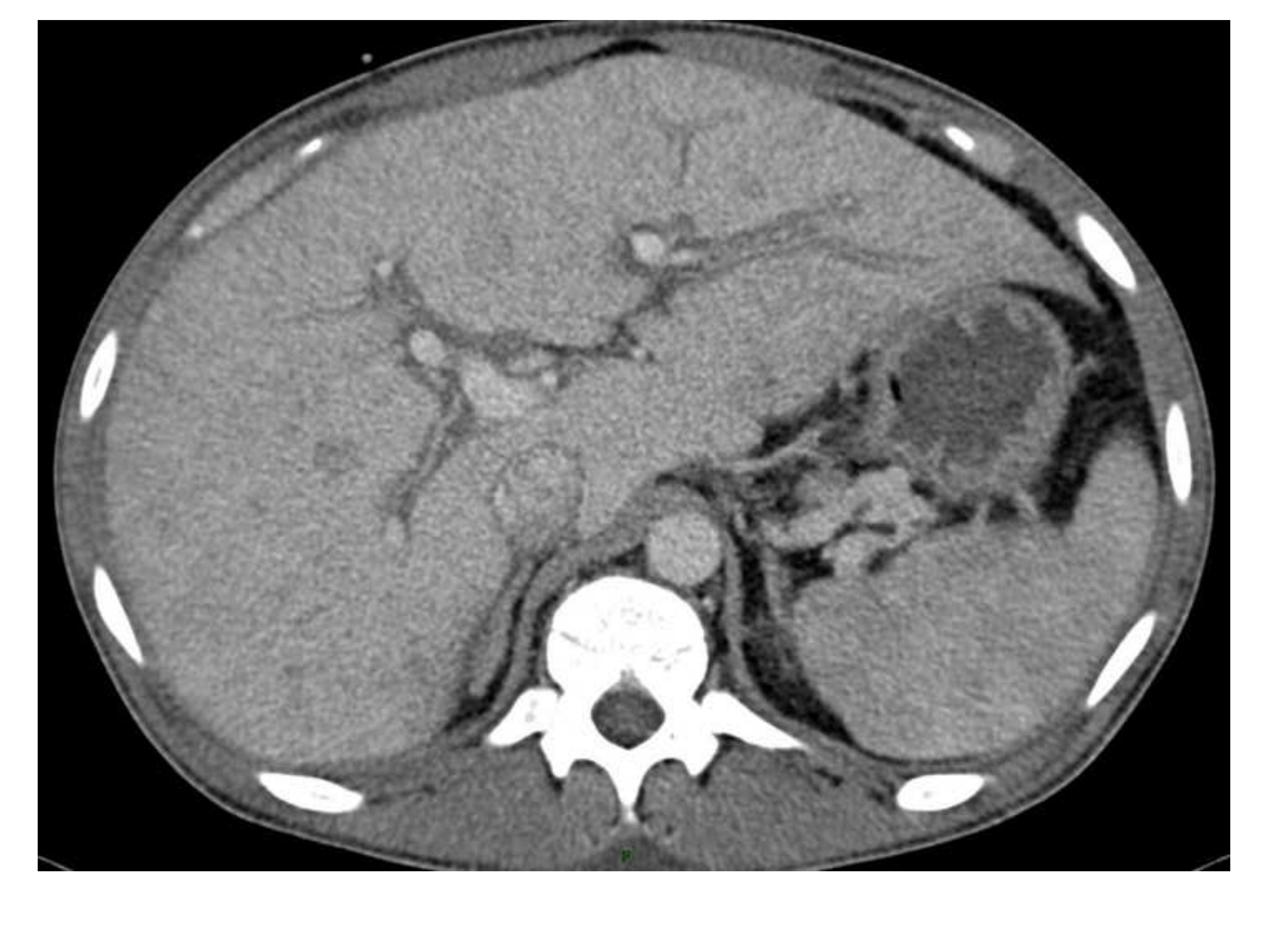
Click here to download Figure Fig 1b.jpg $\underline{\underline{\Perp}}$

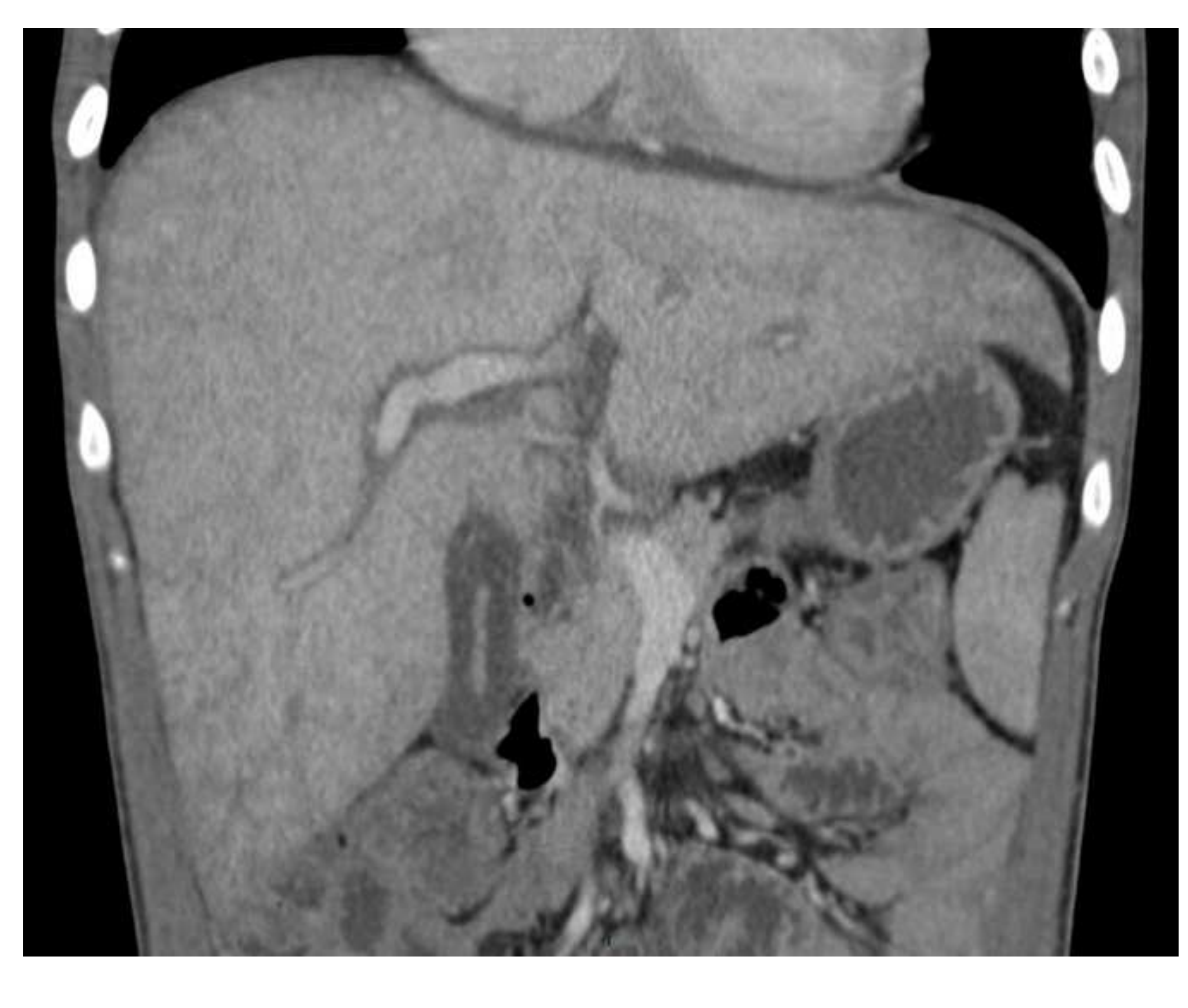

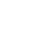
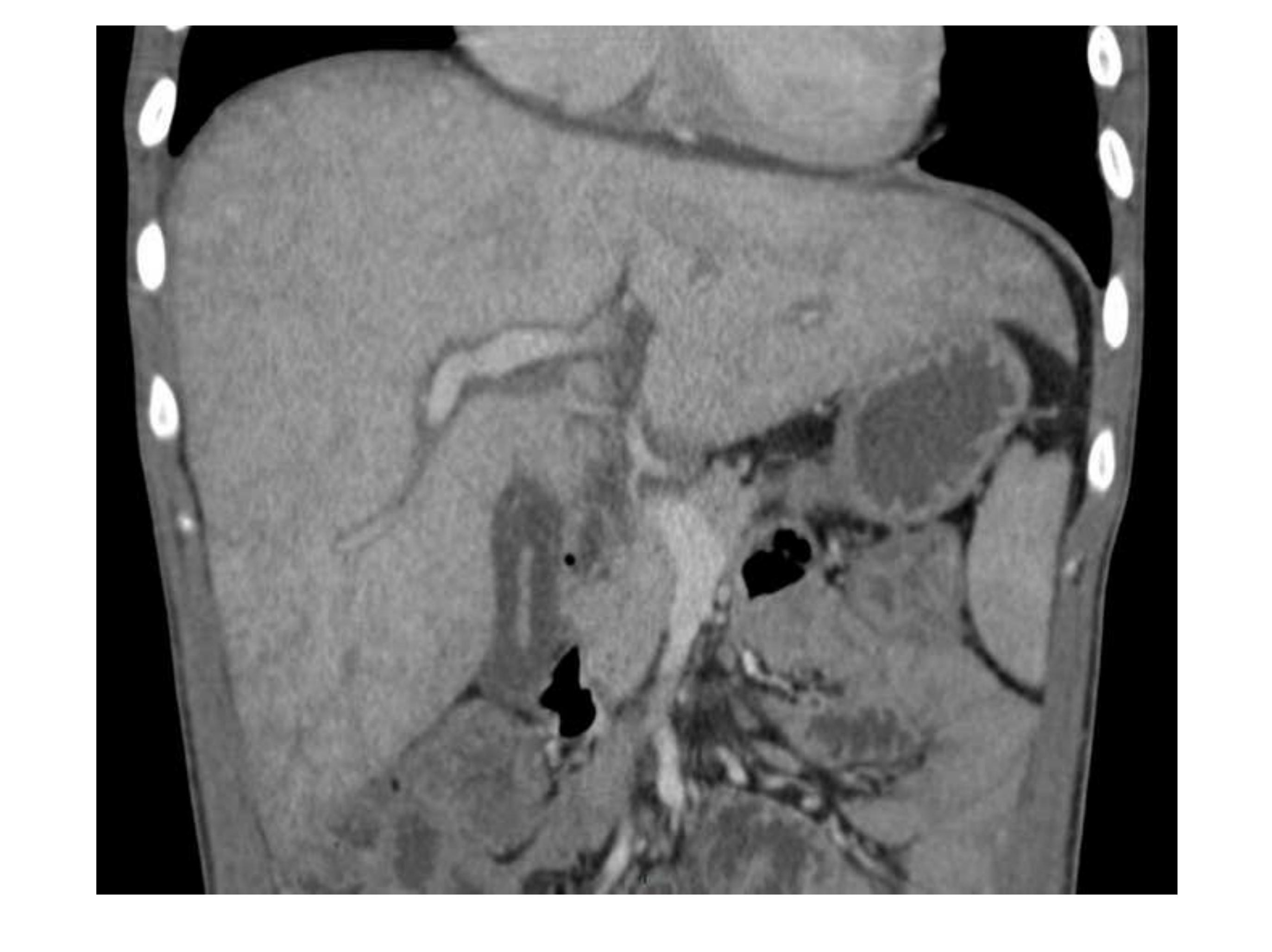
No conflict of interest.

No conflict of interest. 